Portland State University

PDXScholar

$10-21-1988$

\title{
Effects of Flat Panel Display Parameters Across Three Application Areas Upon Similarity Judgments
}

Novia Weiman

Portland State University

Follow this and additional works at: https://pdxscholar.library.pdx.edu/open_access_etds

Part of the Cognition and Perception Commons

Let us know how access to this document benefits you.

Recommended Citation

Weiman, Novia, "Effects of Flat Panel Display Parameters Across Three Application Areas Upon Similarity Judgments" (1988). Dissertations and Theses. Paper 3947.

https://doi.org/10.15760/etd.5831

This Thesis is brought to you for free and open access. It has been accepted for inclusion in Dissertations and Theses by an authorized administrator of PDXScholar. Please contact us if we can make this document more accessible: pdxscholar@pdx.edu. 
AN ABSTRACT OF THE THESIS OF Novia Weiman for the Master of Science in Psychology presented October 21, 1988.

Title: Effects of Flat Panel Display Parameters Across Three Application Areas Upon Similarity Judgments.

APPROVED BY THE MEMBERS OF THE THESIS COMMITTEE:

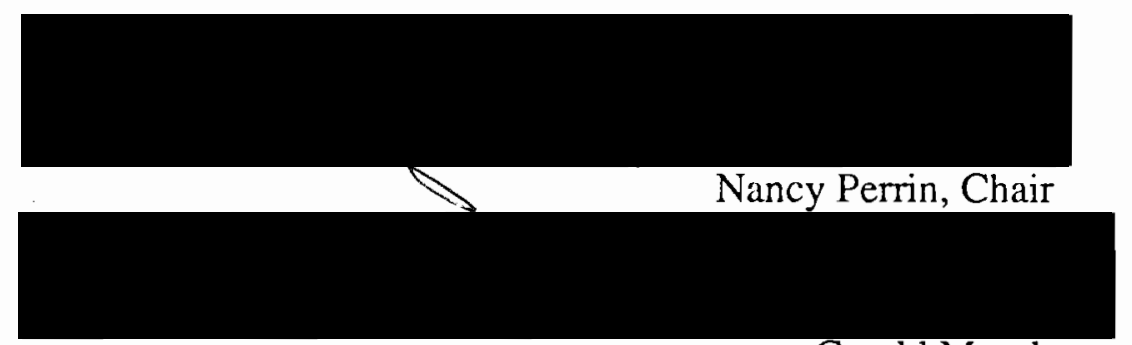

Gerald Murch

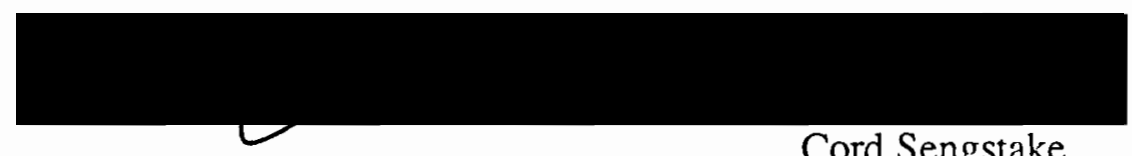

Cord Sengstake

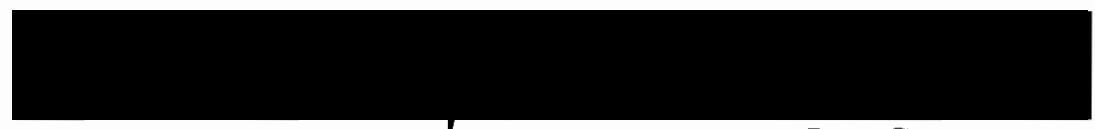

Lee Casperson

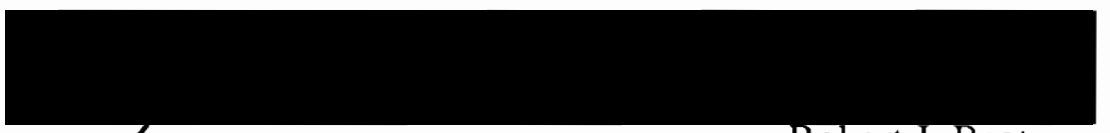

Robert J. Beaton

A human performance experiment was conducted to investigate pixel parameter requirements for three types of flat-panel display images: an alphanumeric character, an oscilloscope waveform, and a real-world image. Subjects performed similarity judgments between an extremely high-quality image and an image composed of different levels of anti-aliasing and pixel width-plus-pixel separation (pitch). It was found that the effect of pitch had greater influence on perceived image quality for the alphanumeric character and 
oscilloscope waveform than for the real-world image. The results of this research provide empirical evidence showirg that the pixel pitch requirements for flat-panel systems that are used to display binary, high-contrast images (such as text and waveforms) will be more stringent than for low-contrast pictorial images. The three levels of grey-scale anti-aliasing investigated were found to improve image quality for only the binary, high-contrast images. 
EFFECTS OF FLAT PANEL DISPLAY PARAMETERS ACROSS

THREE APPLICATION AREAS UPON SIMILARITY JUDGMENTS

by

NOVIA WEIMAN

A thesis submitted in partial fulfillment of the requirements for the degree of

MASTER OF SCIENCE

in

PSYCHOLOGY

Portland State University 
TO THE OFFICE OF GRADUATE STUDIES:

The members of the Committee approve the thesis of Novia Weiman presented October 21, 1988.

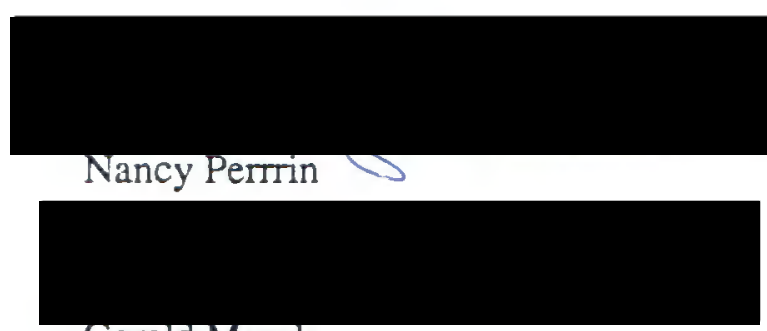

Gerald Murch

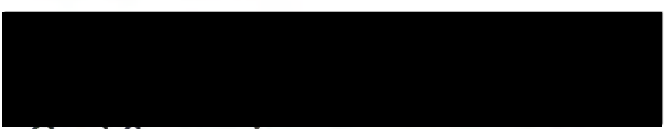

Cord Sengstake
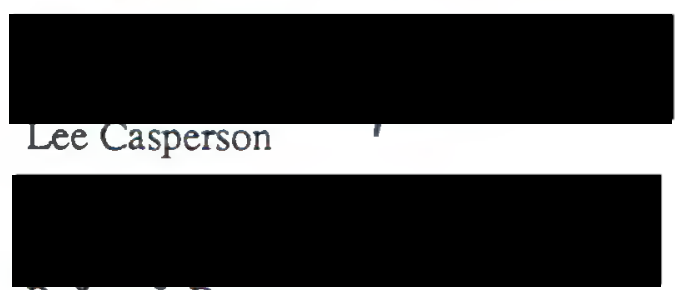

Robert J. Beaton

APPROVED:

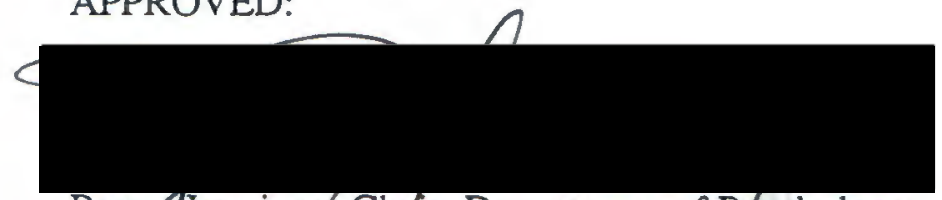

Roget/Jennings, Chqir, Department of P\&ychology

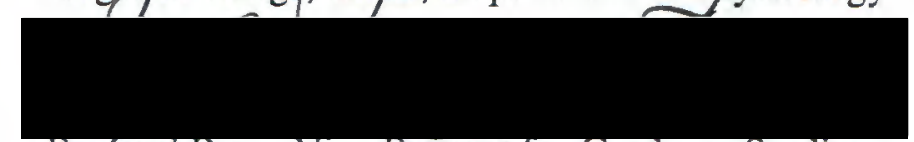

Bernard Ross, Vice Provost for Graduate Studies 


\section{ACKNOWLEDGEMENTS}

I am indebted to both Gerald Murch and Rober J. Beaton for their guidance, support, and patience throughout this project. Without their help, this thesis would not have come to fruition.

I would also like to express my appreciation to Nancy Perrin for her patience and extensive help with the statistical analyses of the research data.

This research was supponed and performed at Tektronix Laboratories, Tektronix, Incorporated. 


\section{TABLE OF CONTENTS}

PAGE

ACKNOWLEDGEMENTS $\ldots \ldots \ldots \ldots \ldots \ldots \ldots \ldots \ldots$ iii

LIST OF TABLES $\ldots \ldots \ldots \ldots \ldots \ldots \ldots \ldots \ldots \ldots$

LIST OF FIGURES $\ldots \ldots \ldots \ldots \ldots \ldots \ldots \ldots \ldots \ldots$ vi

INTRODUCTION $\ldots \ldots \ldots \ldots \ldots \ldots \ldots \ldots \ldots \ldots \ldots \ldots \ldots \ldots \ldots$

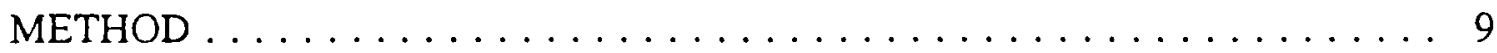

Apparatus $\ldots \ldots \ldots \ldots \ldots \ldots \ldots \ldots \ldots \ldots \ldots \ldots$

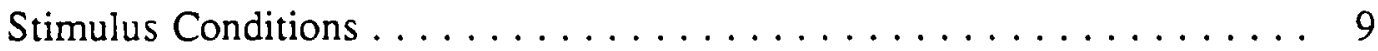

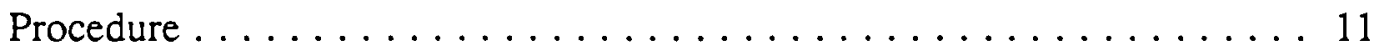

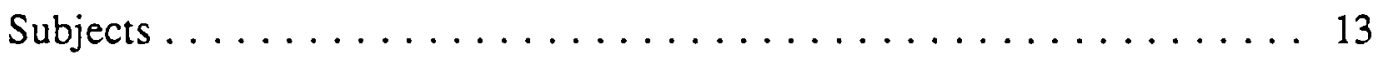

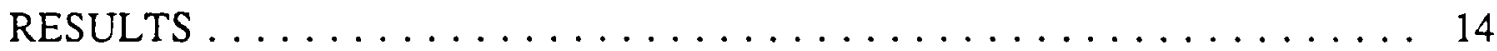

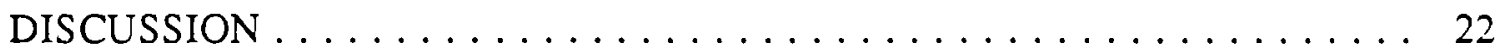

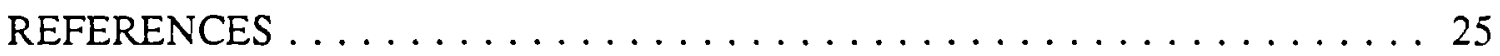

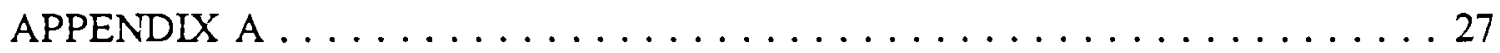

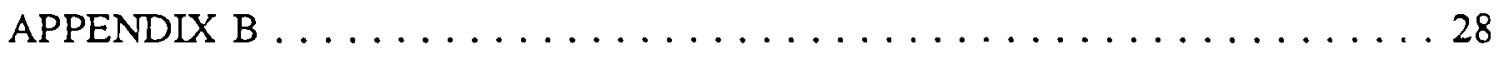

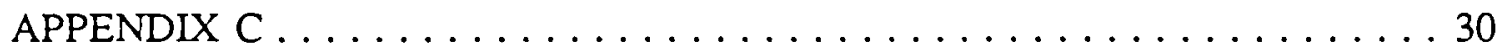

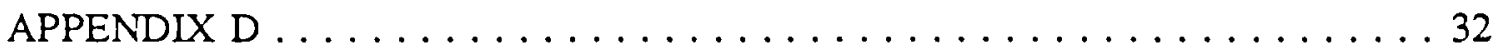




\section{LIST OF TABLES}

TABLE

PAGE

I Results of ANOVA averaged across stimulus type,

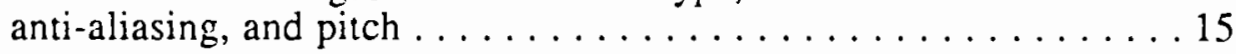




\section{LIST OF FIGURES}

1. Pixel geometry on a flat-panel display system $\ldots \ldots \ldots \ldots \ldots \ldots \ldots$

2. Illustration of 'line jaggies' exhibited on flat-panel displays . . . . . . . 3

3. Example of a grey-scale anti-aliased image $\ldots \ldots \ldots \ldots \ldots \ldots$

4. An oblique flat-panel pixel grid $\ldots \ldots \ldots \ldots \ldots \ldots \ldots \ldots \ldots$

5. Alphanumeric character stimulus with grey-scaling $\ldots \ldots \ldots \ldots \ldots, 11$

6. Example of waveform presented to subjects ............. 11

7. Waveform image composed of diamond pixels ............ 12

8. Waveform image with the 'no processed' pixel condition $\ldots \ldots \ldots \ldots 12$

9. Main effect of anti-aliasing on similarity judgments averaged across 30 subjects . . . . . . . . . . . . . . . . . . . .

10. Main effect of pixel pitch on similarity judgments averaged across

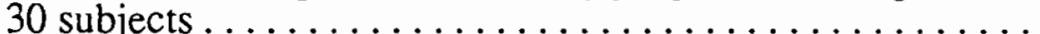

11. Effect of anti-aliasing and pixel pitch on similarity judgments for the waveform image $\ldots \ldots \ldots \ldots \ldots \ldots \ldots \ldots \ldots \ldots \ldots \ldots$

12. Effect of anti-aliasing and pixel pitch on similarity judgments for

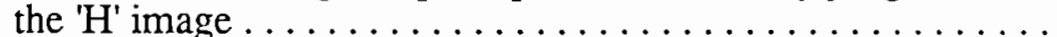

13. Effect of anti-aliasing and pixel pitch on similarity judgments for the 'face' image 


\section{INTRODUCTION}

Electronic displays are devices that convert electrical signals into visual images which can be perceived by the human observer. Serving as the visual interface between man and machine, displays present images within a fraction of a second from the time the information is received. In addition to home entertainment, displays are commonly used to present alphanumeric text, graphical imagery, video pictures, and electronic waveforms. The use of electronic display systems is doubling every few years, and, with the increased use of computers, is often replacing paper as a means for presenting information (Tannas, 1985).

The cathode ray tube (CRT) is one of many electronic display types, and is commonly used in oscilloscopes, aircraft cockpits, and graphic display terminals. The basic elements of a CRT display are the following: a cathode that emits electrons, a gun that is composed of a cathode grid and electron-focusing lens, and a viewing screen coated with a phosphor that emits light when struck with a beam of electrons. CRT displays have been traditionally used to present information to the human user because of numerous advantages, such as: availability in a variety of sizes, capability of displaying high quality images for medical purposes or government intelligence work, and the ability to show numerous colors for computer aided design applications. Despite these benefits, a major downfall to the CRT is the depth required to enclose the electronic elements that comprise the display device. This depth dimension is usually larger than the diagonal measurement of the display screen. 
Flat-panel displays are desirable alternatives to the CRT in that they do not require a sizable depth dimension. A typical flat-panel display is light weight and about one-half irich thick. In the last ten years, there has been considerable progress in the development of commercial flat-panel displays. Much of this progress stems from technological advances in the material sciences and in manufacturing production procedures. Additionally, the availability of economical and reliable flat-panel display products has begun to reshape many electronic display applications. For example, flat-panel display devices are used now in many vehicular and test instrumentation systems. With continuing technological development, flat-panel displays will compete with the conventional cathode-ray tube (CRT) devices in a broad range of applications (Murch, 1987).

More than just physical dimensions are of concern to the electronic flat-panel display designer. The development of any display technology also requires a thorough evaluation of the physical display parameters affecting the viewability of information presented on the screen. This engineering analysis is needed to ensure that the display device provides appropriate levels of image quality; that is, perceived viewability of the displayed information. Although considerable knowledge has been compiled in the past five decades to characterize, quantify, and predict the effects of physical device parameters upon the image quality of electronically displayed information (Snyder, 1973), there is insufficient knowledge concerning the perceptual significance of flat-panel display characteristics. The unique attributes of these devices have hampered the use of previous CRT findings in specifying design guidelines. Specifically, flat-panel displays consist of rectangular pixels that do not overlap one another as in traditional CRT displays (see Figure 1). The pixel geometry of a flat-panel display consists of the height and width of the pixels (element size), the separation between pixels (edge-to-edge spacing), and the pixel pitch, which is the width plus separation of the pixels. For example, given a pixel width of 5 mils and a 
pixel separation of 2 mils, the pixel pitch would equal 7 mils. As shown in Figure 2, this unique pixel geometry can produce image artifacts such as 'line jaggies', in which off-axis lines and edges exhibit a stairstep appearance.

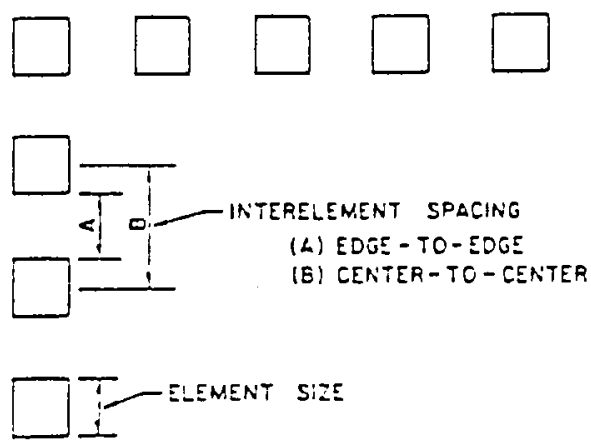

Figure 1. Pixel geometry on a flat-panel display system (Snyder \& Maddox, 1978).

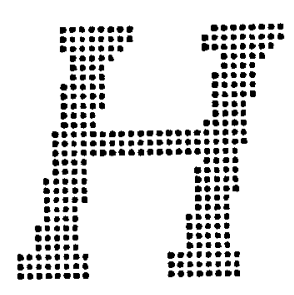

Figure 2. Illustration of 'line jaggies' exhibited on flat-panel displays.

A human factors research program at Tektronix Laboratories has focused on the identification of optimal pixel structure characteristics for flat-panel displays. This research program has investigated the effects of pixel size, pixel symmetry, and edge-to-edge pixel separation on human performance in several task conditions, such as: visual detection threshold, subjective image quality, and legibility of alphanumeric characters.

In the visual detection experiment, subjects viewed various alphanumeric characters that were shown individually on a display screen. Half the trials consisted of characters 
composed of rectangular, non-overlapping pixels, as would be seen on a flat-panel display. The remaining trials consisted of characters that were displayed at the full capability of the display system, and appeared 'perceptually continuous' because there appeared to be no separation between the pixels. Across all trials, the pixels were manipulated in vertical height, horizontal width, and edge-to-edge pixel separation. This experiment found that a pixel pitch equal to six mils $(0.15 \mathrm{~mm})$ or less renders the discrete display panel structures undetectable to the human eye (Beaton $\&$ Knox, 1987). In a related experiment, subjective image quality ratings were obtained for the pixel structures just described. This study found that minimum acceptable levels of subjective image quality correspond to pitches of 10 mils $(0.25 \mathrm{~mm})$ or less, and subjective ratings decreased for pixel pitches greater than 10 mils. A third experiment investigated character legibility across a similar range of pixel size and separation. Subjects were shown four adjacent alphanumeric characters for less than one second. They were instructed to respond by typing in the same four characters on a computer keyboard. This legibility experiment determined that performance was highest for pixel geometries of less than 17 mils (0.43 mm) (Weiman \& Beaton, 1987). These three experiments also demonstrated a two-factor interaction between pixel width and separation. While these results clearly point out the task-dependencies involved in image quality judgments, they also tax current flat-panel design capabilities, where typical display configurations consist of $15 \mathrm{mil}(0.38 \mathrm{~mm})$ wide pixels with two $\mathrm{mil}(0.05 \mathrm{~mm})$ edge-to-edge pixel separations.

Given current hardware design constraints, design engineers are forced to seek novel approaches for reducing the pitch requirements of a display. One approach is the use of grey-scale technology. This technology is used to eliminate jagged edges that would otherwise be apparent in low resolution display systems. Grey-scale refers to the number of shades of grey that can be shown on an electronic display. In general, if each pixel is represented with $n$ bits of brightness, $2^{n}$ different shades of grey are available at each pixel. 
Depending on the capabilities of the display system, the number of grey-scale bits can be as few as two, to as many as eight bits. This technology is used to eliminate jagged edges that are otherwise apparent in low resolution, 1-bit display systems.

A common method for generating a grey-scale image utilizes a technique referred to as anti-aliasing, which employs a mathematical algorithm that presamples a high-frequency image that exhibits sharp, high contrast edges. A low-pass filter is then applied to eliminate the high-frequency information, and a grey-scale image is produced that consists of a gradation of low frequency components as compared to the original image. Figure 3 illustrates the result of an anti-aliasing technique, which has specified different lightness levels across individual pixels lying or the contours of the image (Booth, Bryden, Cowan, Morgan, \& Plante, 1987; Kajiya \& Ullner, 1981; Kingdom \& Moulden, 1986). A typical flat-panel system uses 1 bit of grey-scale where the pixels are either white or black, and results in sharp, jagged borders. A 2 bit grey-scale system is capable of displaying three shades of grey and black. The anti-aliasing algorithm places the gradations of grey in the image in such a way that the 'line jaggies' are reduced. When the display sy'stem is capable of displaying more bits of grey-scale, a greater number of grey shades are employed, which decreases the effect of the line jaggies. It is important to note, however, that this technique of "line-smoothing" is achieved at the expense of slightly blurred edges.

Little research has been reported on the effect of anti-aliasing upon image quality. One study found that the subjective quality of textual images could be improved by using up to 3 bits of grey-scale (Wamock, 1980). Similar results were obtained by Cushman and Miller (1988), who found that 1 bit of grey-scale was sufficient for acceptable legibility of text, but subjective image quality improved up to three grey-scale bits. Another paper reported that subjects preferred anti-aliased images with 3 bits of grey-scale as compared to unprocessed images that contained artifacts (Booth et al., 1987). 


\section{order}

Figure 3. Example of a grey-scale anti-aliased image.

Hardware anti-aliasing methods have been developed as an altemative method to antialiasing accomplished by the system sofware. These hardware methods can also eliminate image arifacts on flat-panel displays. It has been shown that thin lines and gratings are detected more readily when oriented in horizontal or vertical directions as compared to oblique directions (reviewed by Taylor, 1963). Ogilvie and Taylor (1958) determined that the probability of correctly detecting a long, fine wire seen against a bright background was highest at $90^{\circ}$ and $180^{\circ}$ orientation, and lowest at $45^{\circ}$ and $135^{\circ}$. Campbell and Kulikowski (1966) presented stimuli to subjects that consisted of a 'test grating' with a fixed orientation. A second 'masking grating' was superimposed on the 'test grating' and its angle of presentation was altered by the experimenter in relation to the 'test grating'. The effect of grating orientation on contrast sensitivity was measured for six angles. Contrast sensitivity was found to be highest for $0^{\circ}$ and $90^{\circ}$ gratings, and less sensitive for $10^{\circ}, 20^{\circ}$, $30^{\circ}$, and $40^{\circ}$ lines.

Equivalent results were found in an experiment performed by Campbell, Kulikowski, and Levinson (1966). Subjects in this study were given control of the spatial frequency of a sinusoidal grating of fixed, high contrast. The results demonstrated that the horizontal and vertical gratings were detected more often than were the oblique gratings. When low contrast sinusoidal gratings were tested, the results again showed that visual sensitivity was most sensitive in the horizontal and vertical orientations. 
An investigation to determine the difference in visual acuity between vertical and horizontal lines was performed by requiring subjects to view two adjacent grids through a blue or red filter (Beck, 1965). One grid contained horizontal lines, and the other grid consisted of vertical lines. According to the author, the better acuity for vertical lines as compared to horizontally oriented lines was due to astigmatism produced by accommodation and was affected by changes in the vergence of the light rays. Based on this visual perception phenomenon of greater visual sensitivity to vertical and horizontal gratings as opposed to oblique grids, it is assumed that one hardware anti-aliasing method which incorporates obliquely-oriented pixel structures will be less detectable than a verrical-horizontal pixel structure. As shown in Figure 4, pixels are organized in an oblique grid that appears as a diamond-shaped pattern.

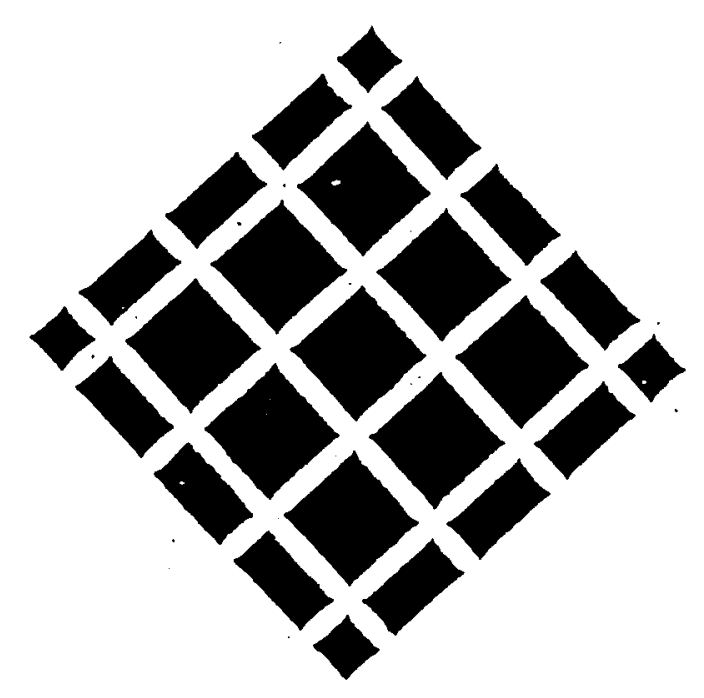

Figure 4. An oblique flat-panel pixel grid. 
Similarly, another viable hardware anti-aliasing technique employs a pixel design with serrated edges, as opposed to straight edges in the horizontal and vertical directions. Since much of the horizontal and vertical edge information would be eliminated, serrated pixel structures should be less detectable than square pixel arrays. Previous research has shown that display pitch is one important factor affecting image quality. Anti-aliasing method is likely another viable factor affecting image quality. These two factors may also influence image quality differently, depending on the type of image displayed. The primary objective of this thesis was to examine the display pitch and anti-aliasing design requirements for flat-panel systems across three classes of images: real-world scenes, alphanumeric characters, and oscilloscope traces. ${ }^{1}$ The study was designed to determine pixel pitches and methods of anti-aliasing that lead to perceived high image quality for each of the three classes of images. Six levels of display pitch and six methods of anti-aliasing were examined for each of the three image types. Extremely high quality, perceptually continuous images were compared to each of the experimental digitized stimuli. Subjects judged the similarity of each experimental image to the continuous image. Those stimuli with high similarity were assumed to be high in image quality. 


\section{METHOD}

\section{APPARATUS}

A large number of display conditions were required for this psychophysical experiment. Since the cost to construct separate display panels for each condition was prohibitive, a high-quality display simulator was developed to simulate the various conditions. This simulator used an extremely high-fidelity CRT monitor (Tektronix, Model GMA-201 with monochrome film-recorder tube, 7 in-diameter $(175 \mathrm{~mm})$ flat faceplate, $\mathrm{P}-45$ phosphor, $0.8 \mathrm{mil}(0.02 \mathrm{~mm})$ spot size, $54 \mathrm{fL}(185.0 \mathrm{~cd} / \mathrm{m} 2)$ peak luminance) and a graphics workstation (Tektronix, Model 4128, $1024 \mathrm{~V}$ by $1280 \mathrm{H}$ pixels by 8 bit addressable frame buffer). The simulator images were displayed within a 1000-line-per-inch active raster area, 1-in (25 mm) vertical by 1.2 -in (30 mm) horizontal, located in the center of the display screen. A laboratory minicomputer (DEC Model VAX8650 ) controlled the display simulator.

\section{STIMULUS CONDITIONS}

The flat-panel conditions manipulated in the experiment included: 1) six leveis of anti-aliasing, 2) six levels of display pitch, and 3) three image types. The anti-aliasing factor consisted of two hardware and three software anti-aliasing techniques, plus a baseline condition. The hardware anti-aliasing conditions were: 1) serrated pixels oriented on the horizontal and vertical axes, and 2) pixels located on a 45 degree grid. The software anti-aliasing conditions manipulated were: 1) 2 grey-scale bits, 2) 3 grey-scale bits, and 3) 
4 grey-scale bits. For the three software anti-aliasing conditions, an algorithm scheme similar to the one described by Kajiya and Ullner (1981) was incorporated in the system software. The baseline image conditions consisted of all six levels of pitch without antialiasing, and were referred to as the 'unprocessed' condition. This provided a basis of comparison between the results for the processed and unprocessed images.

The factor of display pitch consisted of three pixel widths $(5,9$, and 13 mils; 0.13 , 0.23 , and $0.33 \mathrm{~mm}$, respectively), which were factorially combined with two edge-to-edge pixel separations ( 1 and 2 mils; 0.02 and $0.05 \mathrm{~mm}$ ), producing a total of six unique pixel pitch conditions of $6,7,10,11,14$, and 15 mils. Since previous flat-panel display research incorporated these same levels of pixel pitch, it is useful for comparison to use the equivalent pixel parameters.

Three types of images were used in the experiment: 1) a high-quality alphanumeric character (Figure 5), 2) an oscilloscope trace (Figure 6), and 3) a digitized pictorial image. The displayed character was a capital ' $\mathrm{H}$ ' and measured 0.375 in high $\times 0.313$ in wide $(9.38 \mathrm{~mm} \times 7.83 \mathrm{~mm})$. The oscilloscope trace spanned the width of the $1.2 \mathrm{in}(30 \mathrm{~mm})$ display area, and the real-world image, which was composed of a woman's portrait, filled the entire display screen. Each of the three images were crossed with the 36 (6 anti-aliasing $x 6$ pitches) display conditions, creating 108 unique stimuli. Figures 7 and 8 illustrate the anti-aliasing conditions of diamond pixels and no processing for the waveform image.

A black-and-white photograph was taken of the perceptually continuous image that was identical to each of the three types of experimental images. This photograph served as an anchor-point, or comparison standard, for observers when performing similarity judgments, and was located at the top of the CRT. The photograph was the same size as the displayed image. 


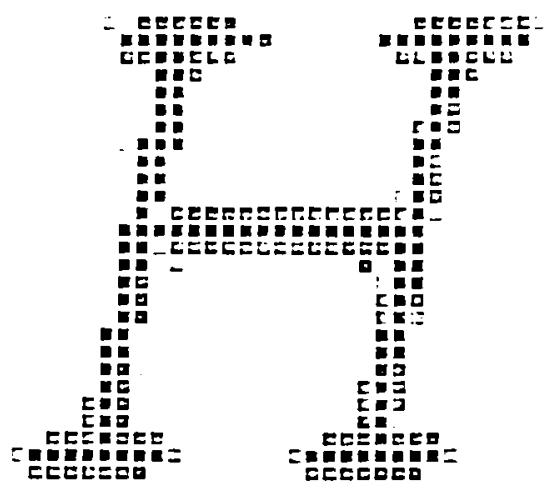

Figure 5 Alphanumeric character stimulus with grey-scaling.

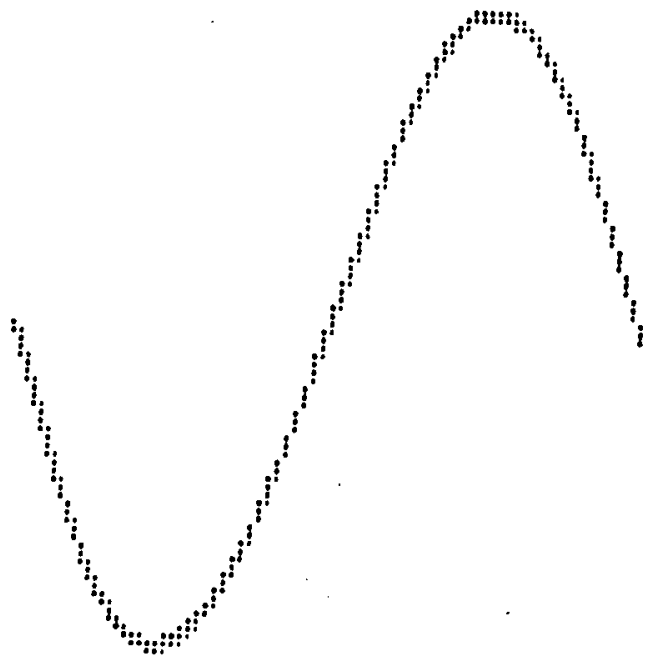

Figure 6. Example of wiaveform presented to subjects.

\section{PROCEDURE}

Subjects performed similarity judgments berween the digitized and continuous images on a 10 -point scale $(1=$ very dissimilar, $10=$ very similar $)$. Every subject viewed only one image type condition. For each experimental trial, subjects pressed a 'Start' key to view one of the experimental images. Each displayed condition was shown for $1.5 \mathrm{sec}$. After signing an Informed Consent Form (see Appendix A), subjects were instructed 


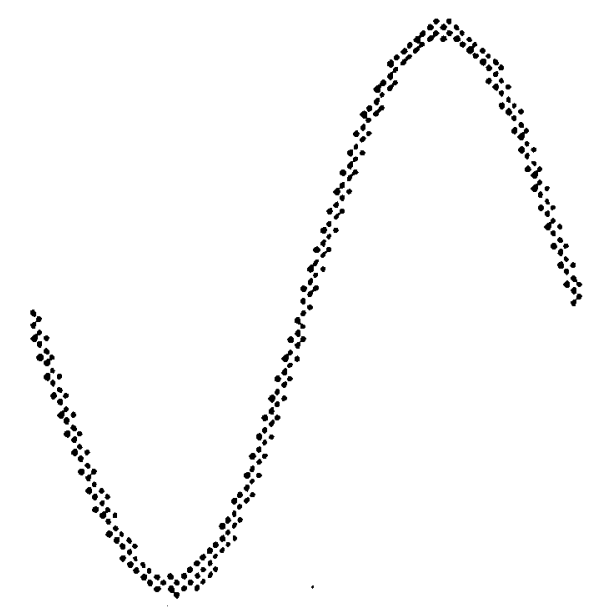

Figure 7. Waveform image composed of diamond pixels.

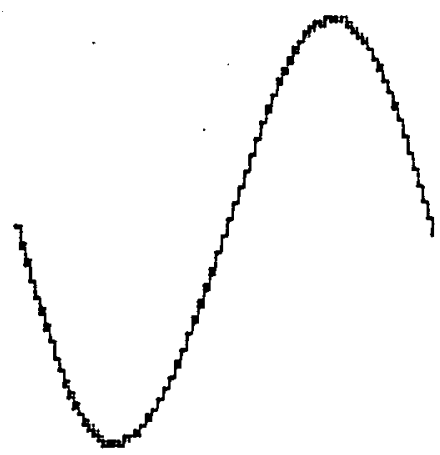

Figure 8. Waveform image with the 'no processed' pixel condition.

to compare the digitized image with the photograph of the continuous image in terms of similarity and to respond by pressing one of the 10 specified keys. Following this response, the subject was prompted to begin the next trial.

Each subject viewed 36 unique stimuli, consisting of the factorial combination of six levels of anti-aliasing and six levels of display pitch for one image type. In addition, each of these 36 judgments were replicated three times, resulting in 108 trials per subject. A mixed-model experimental design was used in which the anti-aliasing and pixel pitch factors were within-subjects manipulations and the image type factor was a between- 
subjects manipulation. Presentation of the experimental conditions was in a unique random order for each subject.

\section{SUBJECTS}

Thirty individuals employed at Tektronix participated in the experiment. Each subject completed the experiment individually in one session, lasting about $45 \mathrm{~min}$. Twenty practice trials were provided to acquaint each subject with the experimental procedure. During the experimental sessions, the testing room was dimly lit with $12 \mathrm{fC}\left(12\right.$ lumen/ $\left./ \mathrm{ft}^{2}\right)$ of diffuse illumination falling on the display faceplate. Subjects were seated 22 in (550 $\mathrm{mm}$ ) from the screen, and were asked to remain at this distance throughout the experimental session. 


\section{RESULTS}

The three replications of similarity judgments were averaged, resulting in 36 observations per subject. The average similarity judgments were then subjected to an Analysis of Variance (ANOVA) procedure. The results of this analysis procedure are shown in Table 1 (SAS, 1985). The mean and standard deviation for each pitch $\mathrm{x}$ antialiasing method $\mathrm{x}$ image type condition are given in Appendices $\mathrm{B}-\mathrm{D}$.

The main effect of anti-aliasing $(F(5,135)=57.86, p=0.0001)$ was found to be statistically significant (Figure 9). A post hoc Newman-Keuls test determined that similarity judgments for 4 bits of grey-scale were significantly different from 3 bits, and there was a significant difference between the serrated pixel condition and 2 bits of greyscale. No significant difference was found between the following four levels of antialiasing technique: 3 bits of grey-scale, diamond pixels, 'no processed', and the serrated pixels $(\alpha=0.05)$.

Pixel pitch $(F(5,135)=198.08, p=0.0001)$ was also found to be a significant main effect (Figure 10). Statistically significant differences were found between the following pitches: 6 and 7 mils, 7 and 10 mils, 10 and 11 mils, as well as 11 and 14 mils. There was no significant difference between pixel pitches of 14 and 15 mils (post hoc NewmanKeuls test, $\alpha=0.05$ ).

It is important to note, however, that these two significant main effects of anti-aliasing and pixel pitch reflect data that were averaged across all three image types. This procedure may be untenable, since each image type cannot be considered equivalent both cognitively and perceptually. 


\section{TABLE I}

\section{RESULTS OF ANOVA AVERAGED ACROSS \\ STIMULUS TYPE, ANTI-ALIASING, AND PITCH}

Source

df

Between Subjects

Image Type [IT]
Subjects w/in IT [S(IT)]

Within Subjects

Anti-aliasing [AA]

$\mathrm{AA} \times \mathrm{IT}$

$\mathrm{AA} \times \mathrm{S}(\mathrm{TT})$

Pitch (P)

$\mathrm{P} \times$ IT

$\mathrm{P} \times \mathrm{S}(\mathrm{IT})$

\section{$A A \times P$}

$A A \times P \times I T$

$\mathrm{AA} \times \mathrm{P} \times \mathrm{S}(\mathrm{IT})$
27

95.97

1.09

0.3506

SS

F

p

Total

282.52
1247.64

135

5
10
135

135

25

50

675

5

0

1247.64

3041.51

752.26

74.93

134.21

1079

7718.40
0.0001

0.0001

57.86
127.77

198.08

0.0001

24.50

0.0001

5.71

5.12

0.0001

0.0001

1079

As expected, the three-factor interaction is statistically significant; therefore, it is informative to discuss the simple two-factor interactions between anti-aliasing and pixel pitch at each level of image type. Figures 11,12 , and 13 present the three-factor interaction among image type, pixel pitch, and anti-aliasing factors.

Figure 11 illustrates the mean similarity judgments for the waveform image across anti-aliasing and pixel pitch. Since this two-factor interaction is significant $(F(25,225)=133.86, p=0.0001)$, post hoc Newman-Keuls tests $(\alpha=0.01)$ were performed to determine significant differences between pixel pitch levels for each antialiasing condition. These results indicate that for 2,3 , and 4 grey-scale bits, all 
Mean

Rating

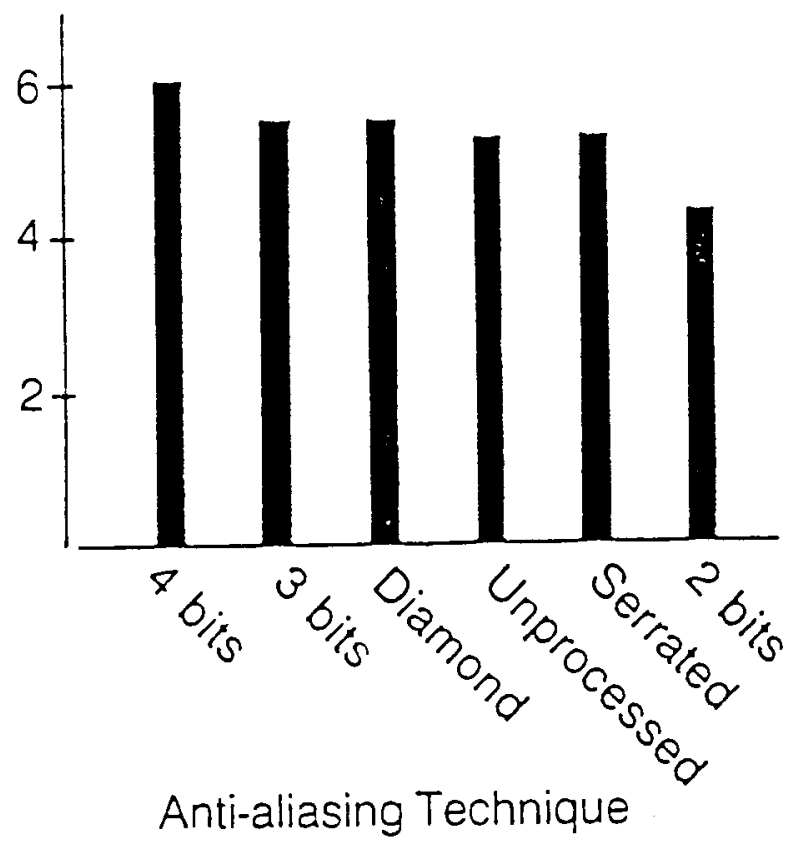

Figure 9. Main effect of anti-aliasing on similarity judgments averaged across 30 subjects.

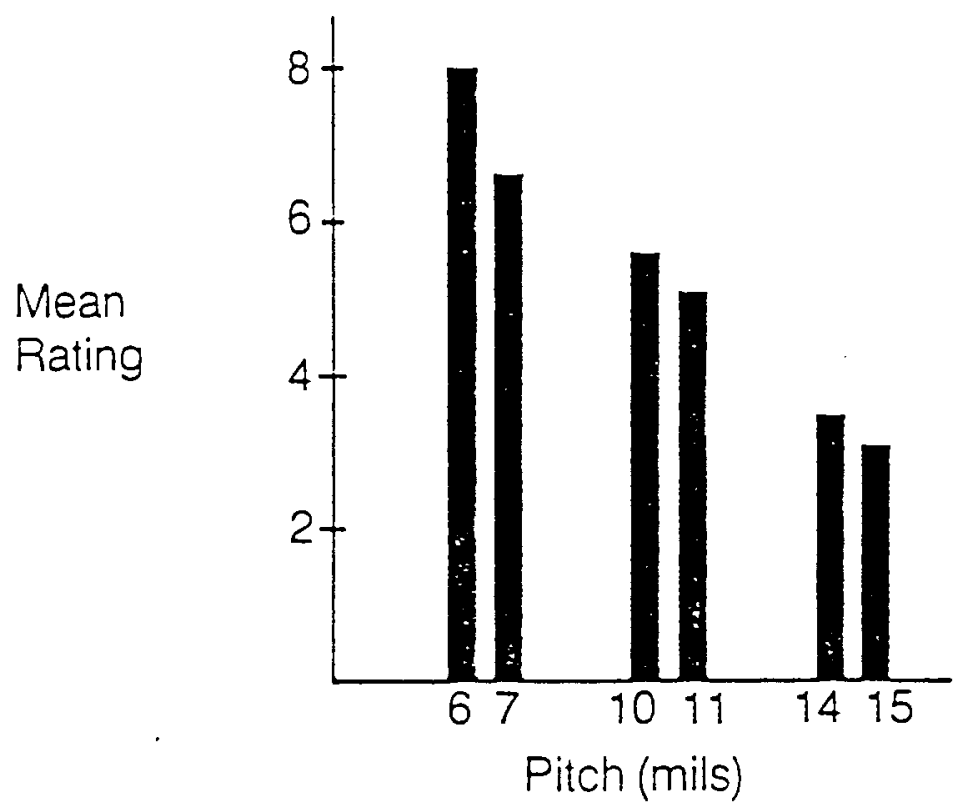

Figure 10. Main effect of pixel pitch on similarity judgments averaged across 30 subjects. 


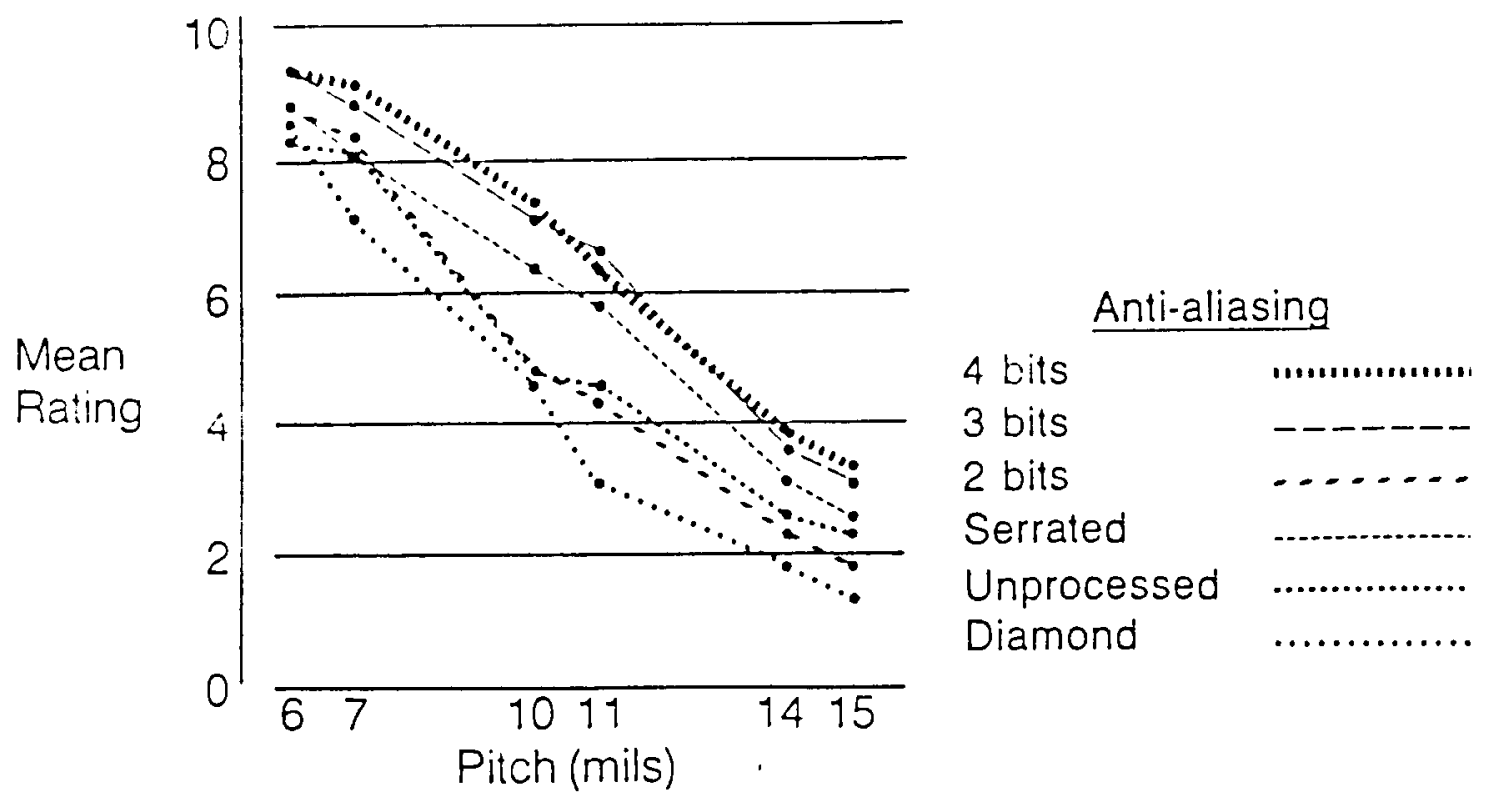

Figure 11. Effect of anti-aliasing and pixel pitch on similarity judgments for the waveform image.

comparisons were significant except the following pairs of pixel pitches: 6 and 7 mils, 10 and 11 mils, and 14 and 15 mils. Therefore, it is evident that for an oscilloscope trace composed of either 2, 3, or 4 bits of grey-scale, a pixel pitch of 7 mils can be used to achieve high similarity to a perceptually continuous image. Any pitch greater than 7 mils is perceived as significantly lower in image quality.

The same pattem of results as above were found for the two anti-aliasing techniques of serrated pixels and the 'no processed' pixels. All comparisons were significant except for the following pixel pitches: 6 and 7 mils, 10 and 11 mils, and 14 and 15 mils. Again, this suggests that for either serrated or unprocessed pixels, a pitch of 7 mils demonstrates the highest performance.

Lastly, for the anti-aliasing level of diamond pixels, all comparisons showed statistically significant differences except for the following: 10 and 11 mils, and 14 and 15 
nils of pixel pitch. This indicates that 6 mils of pitch is necessary for a waveform image that is composed of diamcid pixels to appear the most similar to a continuous image.

Mean similarity judgments for the ' $\mathrm{H}$ ' image across anti-aliasing and pixel pitch are shown in Figure 12. This two-factor interaction is significant $(F(25,225)=4.83$, $p=0.0001)$ and Newman-Keuls tests $(\alpha=0.01)$ were performed on each anti-aliasing technique to determine significant differences between pixel pitch conditions. The results for 2, 3, and 4 bits of grey-scale found significant differences between all pairs except for the following pitches: 10 and 11 mils, and 14 and 15 mils. Since 6 mils is viewed as significantly better in image quality than all other pixel pitches, 6 mils of pixel pitch is required for these conditions of grey-scale to assure best performance.

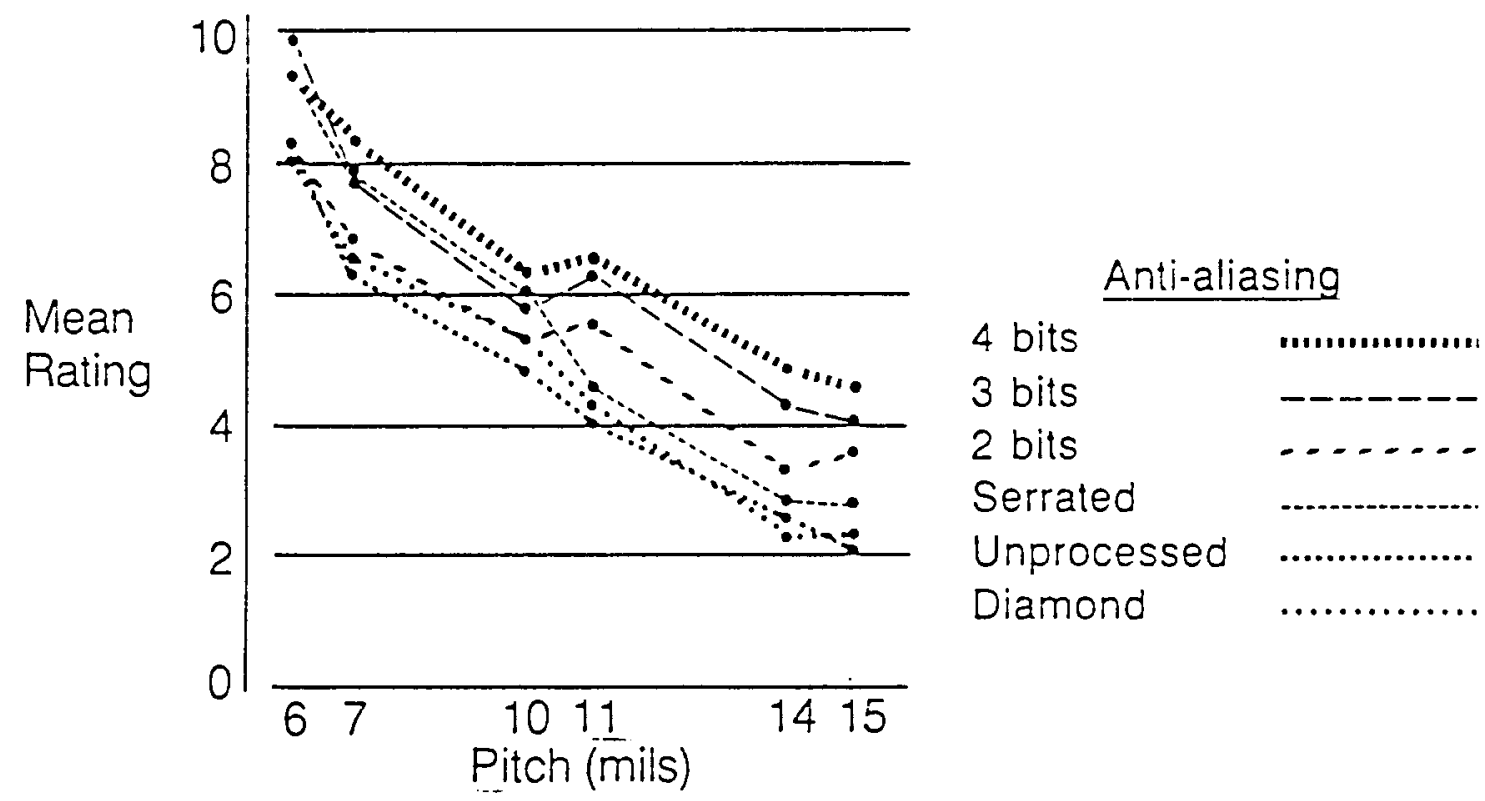

Figure 12. Effect of anti-aliasing and pixel pitch on similarity judgments for the 'H' image.

In terms of the ant-aliasing level of diamond pixels, all pixel pitch comparisons are statistically significant, with the exception of 14 and 15 mils. For the 'no processed' antialiasing level, all comparisons are significandy different except for the following pairs of pitch: 10 and 11 mils, 10 and 14 mils, and 14 and 15 mils. When the ' $H$ ' is composed of 
serrated pixels, all but two pixel pitches are significantly different, and there is no difference in similarity judgments between 10 and 11 mils, and 14 and 15 mils. Thus, for the ' $\mathrm{H}$ ' image, a pixel pitch of 6 mils leads to the greatest similarity to the continuous image for all six anti-aliasing conditions.

Figure 13 shows the mean similarity judgments for the third image type, the 'face', across anti-aliasing and pixel pitch. This two-factor interaction is also statistically significant $(F(25,225)=7.55, p=0.0001)$, and the Newman-Keuls test $(\alpha=0.01)$ was performed to determine significant differences between pixel pitch levels for each antialiasing technique. For 2 bits of grey-scale, there is no significant difference between any two pixel pitches, indicating that a decrease in pitch from 15 mils does not improve performance.

For 3 grey-scale bits, all pixel pitch comparisons are significantly different except: 6 and 7,7 and 10,7 and 11,10 and 11,10 and 14,10 and 15, and 14 and 15 mils. These results indicate that in terms of the real world images, a pixel pitch of either 6 or 7 mils appears to be similar in quality to a perceptually continuous image.

When the 'face' image is composed of 4 bits of grey-scale, all comparisons are significantly different except: 6 and 10 mils, 7 and 10 mils, 7 and 11 mils, 10 and 11 mils, and 14 and 15 mils. Although a pixel pitch of 6 mils leads to the highest similarity judgments, it is not significantly different from 10 mils of pitch, demonstrating that 6 and 10 mils of pitch exhibit the highest performance for similarity to a continuous image.

At the no processing level of anti-aliasing for the 'face', all pitches are significantly different except for the following pairs: 6 and 10 mils, 7 and 11 mils, 7 and 14 mils, 7 and 15 mils, and 11 and 14 mils. In other words, for the unprocessed 'face' image, either 6 or 10 mils exhibits the highest similarity judgments. 


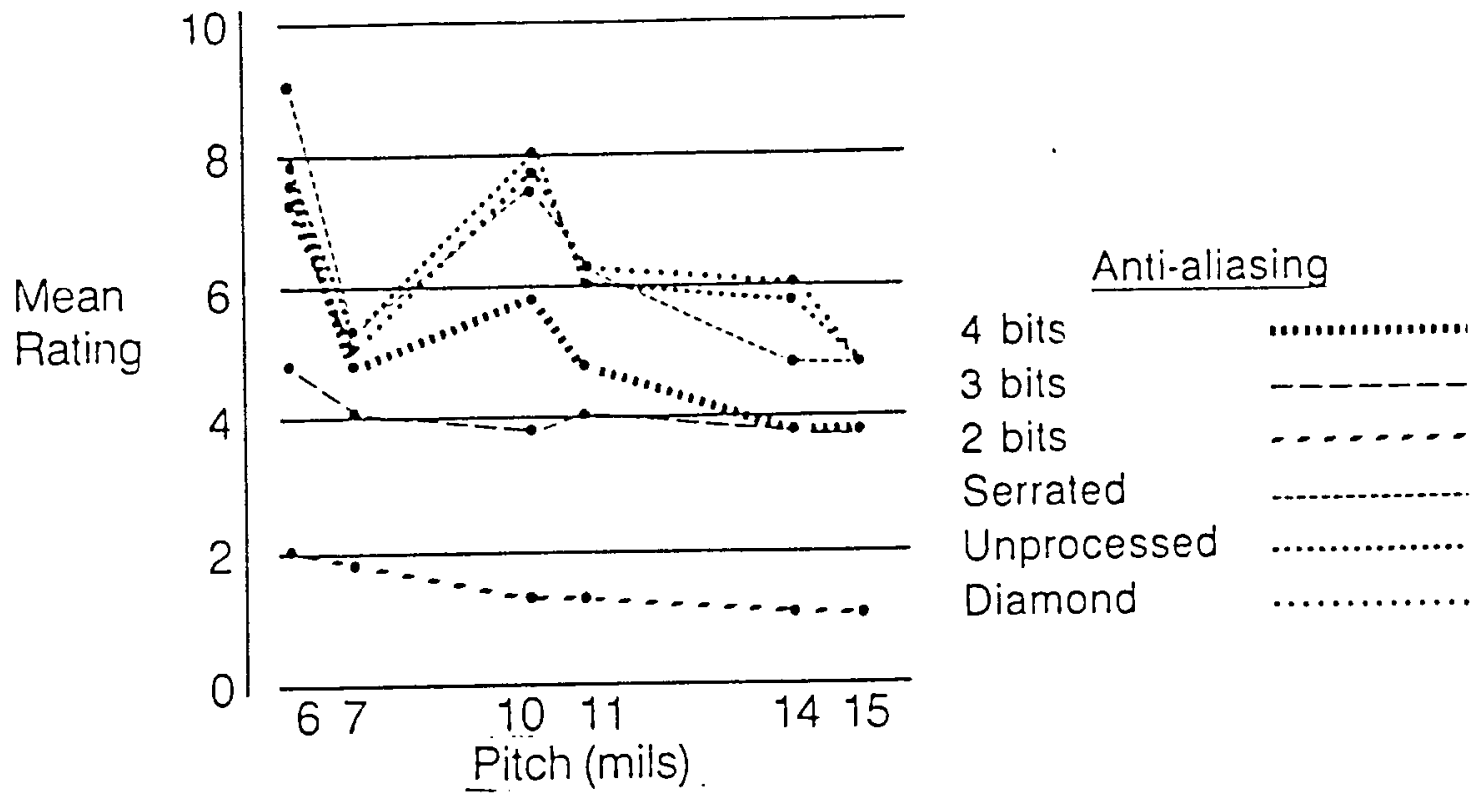

Figure 13. Effect of anti-aliasing and pixel pitch on similarity judgments for the face' image.

For 'face' images comprised of diamond pixels, all comparisons of pitch showed significant differences except: 6 and 10 mils, 7 and 14 mils, 7 and 15 mils, 7 and 11 mils, and 14 and 15 mils of pixel pitch. And, the following pairs of pixel pitch were found to be significant for the serrated pixel condition: 6 and 7 mils, 7 and 10 mils, 10 and 11 mils, and 14 and 15 mils. The performance difference between the pixel pitch of 6 and 10 mils were not found to be significant. Hence, 6 and 10 mils of pixel pitch demonstrate the highest similarity judgments when the 'face' is composed of either one of the following anti-aliasing conditions: diamond, serrated, unprocessed, or 4 bits of grey-scale.

Unlike the other image types, the serrated, 'no processed', diamond pixels, as well as the 4 bits of grey-scale, demonstrated a noticeable reduction in performance from a pixel pitch of 6 to 7 mils, and from a pitch of 10 to 11 mils for the 'face' image. Recall that the 7 
mil pitch consists of 5 mil wide pixels with a 2 mil separation, and pixels that are 9 mils wide with a 2 mil separation comprise an 11 mil pitch. Thus, it is evident that in terms of the 'face' image, the 2 mil pixel separation considerably reduced similarity judgments for all anti-aliasing conditions but the 2 and 3 bits of grey-scale. 


\section{DISCUSSION}

The objective of this experiment was to determine the effect of pixel pitch and antialiasing conditions upon similarity judgments for three classes of images. The main effects of anti-aliasing and pitch were significant, as were the two-factor interaction between these two factors. However, the pattern of the significant two-factor interaction between pitch and anti-aliasing varied across the three image types.

In general, at each level of anti-aliasing for the waveform and alphanumeric images, the perceived similarity to the continuous image decreased as pixel pitch increased in size. Looking at the unprocessed condition for the oscilloscope trace and character images, the effect of increasing display pitch from six to 15 mils caused a four-fold reduction in similarity judgments, suggesting that small display pitches are necessary to achieve high image quality for any type of anti-aliasing among these two types of images. This linear pattern of results was not found for the 'face' image. Instead, performance for the 'no processed' condition demonstrated a two-fold decrease as pixel pitch increased from 6 to 15 mils. This implies that the effect of display pitch exerts greater influence on perceived quality when the image has high-contrast luminance, as the waveform and ' $\mathrm{H}$ ', than for a complex image such as the 'face'. This contention is tenable since the 'face' image contained relatively low contrast and a noisy background as compared to uniformly bright areas comprising the other two images.

This different effect of anti-aliasing across the image types is a reflection of eliminating grey-scale information. That is, without anti-aliasing, the waveform and graphical character were binary images in that they contained 1 bit of grey-scale information. However, when anti-aliased, the grey-scale information in these two images increased to as 
much as 4 bits. Conversely, the aliased real-world image originally contained 8 bits of grey-scale, but the anti-aliasing reduced the information to as low as 2 grey-scale bits.

Since the effects of anti-aliasing and pitch were similar between the oscilloscope trace and graphical character, it is important to examine the attributes of these two image types to determine what is driving performance. In addition to possessing sharp, high-contrast edges, both images exhibited jagged contours. However, for the experimental conditions consisting of the larger pixel pitches, only the graphical character demonstrated a mosaic pattern (tesselations) consisting of light and dark areas inside the contours of the image. Since the oscilloscope trace exhibited jaggies but not tesselations, and the alphanumeric character demonstrated jaggies and tesselations, it is concluded that the similar effect of anti-aliasing and pixel pitch upon similarity judgments for the ' $\mathrm{H}$ ' and waveform images was caused by the jagged edges and not tesselations.

The fact that performance continued to increase for 2,3 , and 4 bits of grey-scale for the 'face' images without ever reaching the level of the unprocessed images suggests that 4 bits of grey-scale is not adequate for producing high quality real-world flat-panel images. This is in contrast to the data available in the literature which suggests that 4 bits of greyscale is sufficient for displayed images (Booth et al., 1987; Cushman, 1988; Warnock, 1980). This recommendation stems from the fact that only binary images were used in the research. The present experiment shows that for the ' $\mathrm{H}$ ' and waveform image, 4 bits of grey-scale leads to the highest perceived image quality when compared to 2 and 3 greyscale bits. Conversely, for high-quality real-world images, these results indicate that all three levels of grey-scale leads to a decrement in image quality. These experimental results for the two binary images concur with previous research, but cannot be generalized to nonbinary images.

Based on previous research demonstrating that the human visual system is less sensitive to oblique lines as compared to grids oriented horizontally or vertically (Campbell 
\& Kulikowski, 1966; Campbell et al., 1966), it was hypothesized that performance would be increased and display pitch requirements reduced by eliminating the horizontal and vertical grid structure with the use of serrated and diamond pixels. In general, however, the results demonstrate that similarity judgments for the unprocessed, diamond, and serrated pixel conditions are similar across the six levels of pixel pitch and three types of images. Thus, pixel pitch requirements are as stringent for diamond and serrated pixels as for unprocessed pixels.

In terms of the waveform and ' $\mathrm{H}$ ' images, 2, 3, and 4 bits of grey-scale lead to higher similarity judgments than do the diamond, serrated, and unprocessed pixels. In other words, for the two types of binary images, grey-scale anti-aliasing leads to higher perceived image quality as compared to the diamond, serrated, and unprocessed conditions. Conversely, for the real-world images, the diamond, serrated, and unprocessed pixels lead to higher similarity judgments than do the three levels of grey-scale anti-aliasing.

For the flat-panel display designer, these results point up the importance of thoroughly specifying the application area in which the display will be utilized before specifying any design recommendations. This experiment provides empirical evidence that pitch requirements for flat-panels are used to display binary, high-contrast images will be more stringent than for pictorial displays. Hence, if a flat-panel is to be configured for use in an instrument where the majority of information will be waveforms or text, the pitch requirements will be about 6 mils, whereas for television images the pitch can be increased to as much as 10 mils. Additionally, grey-scale anti-aliasing is recommended for binary images, but pictorial displays require unprocessed, diamond, or serrated pixels to achieve high quality images. 


\section{REFERENCES}

Beaton, R.J. \& Knox, S.T. 1987. Flat-panel image quality. In Society for Information Display International Sumposium Digest of Technical Papers (pp. 115-118). New Orleans, LA: Palisades Institute for Research Services, Inc.

Beck, J. 1965. Accommodative astigmatism and pattern acuity. Journal of the Optical Society of America, 55, 1139-1142.

Booth, K.S., Bryden, M.P., Cowan, W.B., Morgan, M.F., and Plante, B.L. 1987. On the parameters of human visual performance: an investigation of the benefits of anti-aliasing. IEEE Computer Graphics and Applications, 9 (7) 34-41.

Campbell, F.W. \& Kulikowski, J.J. 1966. Orientational selectivity of the human visual system. Journal of Physiology, 187, 437-445.

Campbell, F.W., Kulikowski, J.J., \& Levinson, J. 1966. The effect of orientation on the visual resolution of gratings. Journal of Phvsiologv, 187, 427-436.

Cushman, W. \& Miller, R. 1988. Resolution and gray-scale requirements for the display of legible alphanumeric characters. In Society for Information Display International Symposium Digest of Technical Papers (pp. 432-434). Anaheim, CA: Sociery for Information Display.

Kajiya, J. \& Ullner, M. 1981. Filtering high quality text for display on raster scan devices. ACM Transactions of Computer Graphics, 15 (3), 7-15.

Kingdom, F. and Moulden, B. 1986. Digitized images: what type of grey scale should one use? Perception, 15, 17-25.

Murch, G. 1987. Human factors and flat panels challenge the CRT. Information Display $3(3), 8-11$.

Ogilvie, J.C. and Taylor, M.M. 1958. Effect of orientation on the visibility of fine wires. Journal of the Optical Society of America, 48 (9), 628-629. 
SAS Institute Inc. 1985. SAS User's Guide: Basics Version 5 Edition. Cary, North Carolina: SAS Institute Inc.

Snyder, H.L. 1973. Image quality and observer performance. In L.M. Biberman (Ed.), Perception of Displayed Information (pp. 87-118). New York, NY: Plenum Press.

Snyder, H.L. and Maddox, M.E. 1978. Information transfer from computer-generated dot-matrix displays. Human Factors Laboratory, Virginia Polytechnic Institute and State University.

Tannas, L.E. 1985. Flat-Panel Displays and CRTs. New York: Van Nostrand Reinhold Co.

Taylor, M.M. 1963. Visual discrimination and orientation. Joumal of the Optical Society of America, 53, 763-765.

Warnock, J.E. 1980. The display of characters using gray level sample arrays. In Proceedings of 1980 ACM-SIGGRAPH, (pp. 302-307). New York, NY: Association for Computing Machinery.

Weiman, N.\& Beaton, R.J. 1987. Effects of flat-panel pixel stuctures upon three human performance measures of image quality. In Aerospace Technology Conference and Exposition (pp. 83-90). Long Beach, CA: Society of Automotive Engineers. 


\section{APPENDLX A}

\section{INFORMED CONSENT FORM}

$\mathrm{I}$, hereby agree to serve as a subject in a flatpanel research experiment conducted by R.J. Beaton and N. Weiman.

I understand that the study requires about one hour of participation, in which I will be performing similarity judgments on pairs of images.

I understand that participation in the experiment will take place during normal working hours (8:00 am - 6:00 pm).

It has been explained to me that the purpose of the study is to determine the effects of pixel structure and anti-aliasing techniques upon perceived image quality judgments.

I may not receive any direct benefit from participation in this study, but my participation may help to increase knowledge which may benefit others in the future.

Novia Weiman has offered to answer any questions I may have about the study and what is expected of me in the study. I have been assured that all information I give will be kept confidential and that the identity of all subjects will remain anonymous.

I also understand that I am free to withdraw from participation in this experiment at any time.

I have read and understand the foregoing information.

Date Signature

If you experience problems that are the result of your participation in this experiment, please contact the Office of Grants and Contracts, Portland State University, 464-3417. 


\section{APPENDIX B}

\section{TABLED MEANS AND STANDARD \\ DEVIATIONS FOR THE \\ WA VEFORM IMAGE}

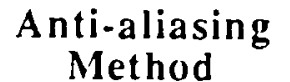

Pitch

(mils)
Mean Similarity Judgment
Standard

Deviation

\begin{tabular}{|c|c|c|c|}
\hline $\begin{array}{c}\text { Diamond } \\
\text { " } \\
" \\
" \\
"\end{array}$ & $\begin{array}{c}6 \\
7 \\
10 \\
11 \\
14 \\
15\end{array}$ & $\begin{array}{l}8.33 \\
7.27 \\
4.40 \\
3.43 \\
1.90 \\
1.47\end{array}$ & $\begin{array}{l}1.47 \\
1.40 \\
1.72 \\
1.81 \\
1.03 \\
0.82\end{array}$ \\
\hline $\begin{array}{c}\text { No Processing } \\
" \\
" \\
" \\
"\end{array}$ & $\begin{array}{l}6 \\
7 \\
10 \\
11 \\
14 \\
15\end{array}$ & $\begin{array}{l}8.83 \\
8.10 \\
4.97 \\
4.30 \\
2.13 \\
1.80\end{array}$ & $\begin{array}{l}1.06 \\
1.29 \\
1.74 \\
1.72 \\
0.95 \\
0.86\end{array}$ \\
\hline $\begin{array}{c}\text { Serrated } \\
\text { " } \\
" \\
" \\
" \\
"\end{array}$ & $\begin{array}{l}6 \\
7 \\
10 \\
11 \\
14 \\
15\end{array}$ & $\begin{array}{l}8.37 \\
8.07 \\
4.73 \\
4.53 \\
2.43 \\
2.30\end{array}$ & $\begin{array}{l}1.34 \\
1.29 \\
1.19 \\
1.68 \\
0.85 \\
1.18\end{array}$ \\
\hline $\begin{array}{c}2 \text { bits } \\
" \\
" \\
" \\
" \\
"\end{array}$ & $\begin{array}{c}6 \\
7 \\
10 \\
11 \\
14 \\
15\end{array}$ & $\begin{array}{l}8.73 \\
8.23 \\
6.37 \\
5.87 \\
3.03 \\
2.63\end{array}$ & $\begin{array}{l}1.25 \\
1.61 \\
1.65 \\
1.26 \\
1.09 \\
0.96\end{array}$ \\
\hline $\begin{array}{c}3 \text { bits } \\
" \\
" \\
" \\
"\end{array}$ & $\begin{array}{c}6 \\
7 \\
10 \\
11 \\
14 \\
15\end{array}$ & $\begin{array}{l}9.13 \\
8.83 \\
7.13 \\
6.53 \\
3.70 \\
3.33\end{array}$ & $\begin{array}{l}0.89 \\
1.14 \\
1.27 \\
1.18 \\
1.33 \\
1.40\end{array}$ \\
\hline
\end{tabular}




\section{4 bits}

"'

1

"

"
6

10

11

14

15
9.10

8.93

7.40

6.47

3.97

3.43
0.63

1.07

1.24

1.41

0.97

1.04 


\section{APPENDIX C}

\section{TABLED MEANS AND STANDARD \\ DEVIATIONS FOR THE ALPHA- NUMERIC CHARACTER}

\begin{tabular}{|c|c|c|c|}
\hline $\begin{array}{l}\text { Anti-aliasing } \\
\text { Method }\end{array}$ & $\begin{array}{l}\text { Pitch } \\
\text { (mils) }\end{array}$ & $\begin{array}{c}\text { Mean Similarity } \\
\text { Judgment }\end{array}$ & $\begin{array}{l}\text { Standard } \\
\text { Deviation }\end{array}$ \\
\hline $\begin{array}{c}\text { Diamond } \\
" " \\
" \\
" \\
" \\
"\end{array}$ & $\begin{array}{l}6 \\
7 \\
10 \\
11 \\
14 \\
15\end{array}$ & $\begin{array}{l}9.83 \\
7.93 \\
6.03 \\
4.50 \\
2.83 \\
2.63\end{array}$ & $\begin{array}{l}0.32 \\
1.33 \\
1.88 \\
1.94 \\
1.85 \\
1.76\end{array}$ \\
\hline $\begin{array}{c}\text { No Processing } \\
" \\
" \\
" \\
" \\
"\end{array}$ & $\begin{array}{c}6 \\
7 \\
10 \\
11 \\
14 \\
15\end{array}$ & $\begin{array}{l}8.20 \\
6.50 \\
3.77 \\
4.13 \\
2.77 \\
2.23\end{array}$ & $\begin{array}{l}0.93 \\
1.77 \\
1.88 \\
1.87 \\
2.04 \\
1.63\end{array}$ \\
\hline $\begin{array}{c}\text { Serrated } \\
" \\
" \\
" \\
" \\
"\end{array}$ & $\begin{array}{c}6 \\
7 \\
10 \\
11 \\
14 \\
15\end{array}$ & $\begin{array}{l}8.10 \\
6.57 \\
3.27 \\
4.40 \\
2.17 \\
2.23\end{array}$ & $\begin{array}{l}1.05 \\
1.78 \\
2.05 \\
2.24 \\
1.65 \\
1.56\end{array}$ \\
\hline $\begin{array}{c}2 \text { bits } \\
" \\
" \\
" \\
"\end{array}$ & $\begin{array}{c}6 \\
7 \\
10 \\
11 \\
14 \\
15\end{array}$ & $\begin{array}{l}8.33 \\
6.93 \\
5.43 \\
5.60 \\
3.43 \\
3.50\end{array}$ & $\begin{array}{l}1.32 \\
1.91 \\
1.77 \\
1.84 \\
1.74 \\
2.04\end{array}$ \\
\hline $\begin{array}{c}3 \text { bits } \\
" \\
" \\
" \\
"\end{array}$ & $\begin{array}{l}6 \\
7 \\
10 \\
11 \\
14 \\
15\end{array}$ & $\begin{array}{l}9.20 \\
7.77 \\
5.83 \\
6.13 \\
4.43 \\
4.00\end{array}$ & $\begin{array}{l}0.97 \\
1.64 \\
1.63 \\
1.63 \\
1.79 \\
2.29\end{array}$ \\
\hline
\end{tabular}


4 bits

"

"1

"

"

"1
6

10

11

4

15
9.37

8.20

6.27

6.40

4.87

4.70
0.51

1.45

1.61

1.70

1.65

2.25 


\section{APPENDLX D}

\section{TABLED MEANS AND STANDARD \\ DEVIATIONS FOR THE \\ 'FACE' IMAGE}

\begin{tabular}{|c|c|c|c|}
\hline $\begin{array}{c}\text { Anti-aliasing } \\
\text { Method }\end{array}$ & $\begin{array}{l}\text { Pitch } \\
\text { (mils) }\end{array}$ & $\begin{array}{c}\text { Mean Similarity } \\
\text { Judgment }\end{array}$ & $\begin{array}{l}\text { Standard } \\
\text { Deviation }\end{array}$ \\
\hline $\begin{array}{c}\text { Diamond } \\
" " \\
" \\
" \\
" \\
"\end{array}$ & $\begin{array}{c}6 \\
7 \\
10 \\
11 \\
14 \\
15\end{array}$ & $\begin{array}{l}8.50 \\
5.47 \\
7.77 \\
6.47 \\
4.87 \\
4.87\end{array}$ & $\begin{array}{l}1.15 \\
1.72 \\
1.65 \\
1.51 \\
1.17 \\
1.08\end{array}$ \\
\hline $\begin{array}{c}\text { No Processing } \\
" \\
" \\
" \\
"\end{array}$ & $\begin{array}{c}6 \\
7 \\
10 \\
11 \\
14 \\
15\end{array}$ & $\begin{array}{l}7.83 \\
5.33 \\
8.27 \\
6.23 \\
5.93 \\
4.77\end{array}$ & $\begin{array}{l}1.66 \\
1.42 \\
1.55 \\
1.62 \\
1.39 \\
1.07\end{array}$ \\
\hline $\begin{array}{c}\text { Serrated } \\
" \\
" \\
" \\
" \\
"\end{array}$ & $\begin{array}{c}6 \\
7 \\
10 \\
11 \\
14 \\
15\end{array}$ & $\begin{array}{l}7.30 \\
5.20 \\
7.90 \\
6.43 \\
6.23 \\
4.93\end{array}$ & $\begin{array}{l}1.80 \\
1.69 \\
0.97 \\
1.44 \\
1.56 \\
1.17\end{array}$ \\
\hline $\begin{array}{c}2 \text { bits } \\
" " \\
" \\
" \\
"\end{array}$ & $\begin{array}{c}6 \\
7 \\
10 \\
11 \\
14 \\
15\end{array}$ & $\begin{array}{l}2.00 \\
1.83 \\
1.67 \\
1.67 \\
1.33 \\
1.33\end{array}$ & $\begin{array}{l}0.80 \\
0.95 \\
0.74 \\
0.70 \\
0.77 \\
0.38\end{array}$ \\
\hline $\begin{array}{c}3 \text { bits } \\
" \\
" \\
" \\
" \\
"\end{array}$ & $\begin{array}{c}6 \\
7 \\
10 \\
11 \\
14 \\
15\end{array}$ & $\begin{array}{l}4.97 \\
4.17 \\
3.87 \\
4.00 \\
2.83 \\
2.80\end{array}$ & $\begin{array}{l}1.80 \\
2.05 \\
1.71 \\
1.60 \\
1.39 \\
1.14\end{array}$ \\
\hline
\end{tabular}




$\begin{array}{cc}4 \text { bits } & 6 \\ " & 7 \\ " & 10 \\ " & 11 \\ " & 14 \\ \text { " } & 15\end{array}$

6.63

4.97

5.83

4.93

3.73

3.77
1.59

1.59

1.38

1.38

1.31

1.16 